\title{
Acción participativa, interacción y conocimiento en situaciones de aprendizaje artístico en el entorno urbano.
}

\section{Participatory action, interaction, and knowledge in artistic learning situations in the urban environment.}

\author{
Elke Castro León \\ Universidad de Sevilla/Universidad \\ Internacional de La Rioja (España) \\ elke.castro@unir.net
}

Recibido: 07/08/2020 Revisado: 08/11/2020

Aceptado: 02/01/2021 Publicado: 14/01/2021

\section{Resumen:}

Esta investigación explora las ventajas metodológicas que nos brindan las situaciones de aprendizaje del arte que suceden en entornos públicos. En la experiencia propuesta, se emplea la fotografía como herramienta pedagógica y medio de expresión visual protagonista del proceso de enseñanza-aprendizaje, situando la creación de imágenes en el centro de la actividad pedagógica en artes visuales. Al mismo tiempo, la organizadora de la acción educativa interviene como artista-investigadora- educadora que hace uso de la fotografía como instrumento de Investigación Basada en Artes y recurso eficiente para evidenciar los acontecimientos generadores del conocimiento artístico que tienen lugar en el proceso. Mediante la exploración multisensorial, la interacción, la participación y la colaboración apreciar arte se transforma en un acto de producción colectiva decultura en el cual los estudiantes se reconocen como creadores de imágenes y no solo como consumidores de esta cultura. Vinculando la práctica, la reflexión y el aprendizaje, este tipo de experiencias estéticas y educativas se muestran favorecedoras del aumento de la curiosidad y la participación, así como también del disfrute personal, logrando de este modo, un mayor acercamiento de los participantes a la obra de arte.

Sugerencias para citar este artículo:

Castro León, Elke (2021). Acción participativa, interacción y conocimiento en situaciones de aprendizaje artístico en el entorno urbano. Tercio Creciente 19, (pp. 33-45), https://dx.doi.org/10.17561/rtc.19.5704

CASTRO LEÓN, ELKE. Acción participativa, interacción y conocimiento en situaciones de aprendizaje artístico en el entorno urbano. Tercio Creciente, diciembre 2021, pp. 33-45, https://dx.doi.org/10.17561/rtc.19.5704 
DOI: https://dx.doi.org/10.17561/rtc.19.5704 Investigación
La cuestión imaginativa: del dibujo y la fotografía a la imagen en movimiento

\begin{abstract}
:
This research explores the methodological advantages that art learning situations that occur in public settings provide us with. In the proposed experience, photography is used as a pedagogical tool and means of visual expression as the protagonist of the teaching-learning process, placing image creation at the heart of the pedagogical activity in visual arts. At the same time, the organiser of educational action intervenes as an artist-researcher-teacher who makes use of photography as an Arts-based Research instrument and efficient resource to highlight the events of artistic knowledge that take place in the process. Through multisensory exploration, interaction, participation and collaboration, appreciating art becomes an act of collective production of culture in which students recognise themselves as producers of images and not only as consumers of this culture. Linking practice, reflection and learning, these kinds of aesthetic and educational experiences are fostering curiosity and participation, as well as personal enjoyment, thus achieving a closer approximation of the participants to the work of art.
\end{abstract}

\title{
Palabras Clave / Keywords
}

Investigación Basada en Artes, etnografía visual, a/r/tografía, fotografía, proceso artístico colaborativo, interacción social, Chillida

Arts-based Research, visual ethnography, a/r/tography, photography, collaborative artistic process, social interaction, Chillida

Sugerencias para citar este artículo:

Castro León, Elke (2021). Acción participativa, interacción y conocimiento en situaciones de aprendizaje artístico en el entorno urbano. Tercio Creciente 19, (pp. xx-xx), https://dx.doi.org/10.17561/rtc. 19.5704

CASTRO LEÓN, ELKE. Acción participativa, interacción y conocimiento en situaciones de aprendizaje artístico en el entorno urbano. Tercio Creciente, diciembre 2021, pp. xx-xx, https://dx.doi.org/10.17561/rtc. 19.5704

\section{Introducción}


La obra de arte situada en un entorno público incita al espectador a interactuar como sujeto activo con el objeto de conocimiento (Piaget, 2012). La pieza escultórica de gran formato, a través de la exploración multisensorial, espacial, etc. y mediante la interacción con el otro (Vygotski, 1984, 1995), interviene como verdadero motor de desarrollo cognitivo del espectador, junto con el intercambio de puntos de vista entre sus iguales y el adulto (artista-investigadora-educadora), que se constituyen como mediadores fundamentales en la experiencia de apreciación.

De este modo, mediante el aprendizaje experiencial (Dewey, 2002, 2004) se ponen a disposición del individuo situaciones (Coll, 1991) y contenidos relevantes al tiempo que se generan espacios propicios para la construcción de aprendizajes significativos (Ausubel, Novak y Hanesian, 1987; Moreira, 2000). En este sentido, reseñar la importancia que cobra durante el diseño de este tipo de prácticas la adecuada contextualización de estas a la realidad del alumnado; sus motivaciones, necesidades y sus vivencias previas, de manera que sea posible lograr un equilibrio entre tales experiencias con los conceptos necesarios para alcanzar los objetivos de aprendizaje propuestos. Al tiempo, cabe destacar igualmente la pertinencia de hacer implícita en esta manera de entender el proceso de aprendizaje, así como también la necesidad derivada de la práctica, de la adquisición de habilidades que le sean de utilidad a los estudiantes en su contexto extraescolar y quehacer diario.

Por otra parte, en conexión con la actividad realizada se produce un aprendizaje incidental, o lo que es lo mismo, que es llevado a cabo sin esfuerzo. Así pues, mientras que la actividad principal centra su atención en el conocimiento, la comprensión y la apreciación de las cualidades de la escultura (valor perceptivo), los estudiantes aprenden a trabajar con la fotografía para expresarse y comunicar ideas, experiencias y emociones propias (valor creativo y expresivo) (Benjamin y Muñoz Millanes, 2007) sin que en ningún momento estos sean instruidos al respecto de posicionamiento de la cámara, planos, encuadres, luces, ... o cualquier otro concepto que pudiera estar vinculado con la acción artística concreta.

El planteamiento teórico descrito y tomado en consideración para el diseño y planificación de la propuesta educativa muestra un nuevo desempeño en el papel del alumno que mantiene en todo momento la motivación hacia el aprendizaje siendo autónomo y consciente de ser responsable de su propio aprendizaje (Orden 
$E C D / 65 / 2015$, de 21 de enero, por la que se describen las relaciones entre las competencias, los contenidos y los criterios de evaluación de la educación primaria, la educación secundaria obligatoria y el bachillerato).

2. El importante papel de la interacción social y las emociones en la construcción del conocimiento artístico

Los aprendizajes mutuos llevados a cabo en el contexto de convivencia que se propone en la actividad pedagógica determinada resultan de la construcción compartida de conocimientos (Colomina y Onrubia, 2001). Al hilo de esta idea, conviene pues, resaltar la importancia de lo colectivo en las prácticas educativas, así como la importancia también que adquieren en dicho asunto los intercambios e interacciones acontecidos en el contexto experiencial, significando al tiempo que, solo es posible que se produzcan tales aprendizajes grupales en el medio de la comunicación, no pudiendo existir en ningún caso, fuera de este ámbito.

El conocimiento es construido a través de complejas redes de intercambio social, que irán constituyendo su estructura conceptual o sistema de interpretación, y a partir del cual el estudiante va fundando sus propios significados y representaciones sobre el arte y la práctica artística. (Castro-León, 2017, p.54)

Únicamente, si los individuos participantes se esfuerzan en conseguir establecer un marco referencial común (Coll, 1991) podrán estos alcanzar la capacidad que Bruner (1997) dio en llamar como intersubjetividad, entendiendo esta como subjetividad socialmente compartida por la comunidad en interacción, gracias a la cual se hace posible el intercambio de significados y la construcción conjunta del conocimiento, ya sea este artístico o de cualquier otra índole.

Con la práctica implementada, donde se combina la percepción, la experiencia, la cognición y el comportamiento, se evidencia el proceso de construcción del conocimiento artístico como un suceso natural y holístico. 


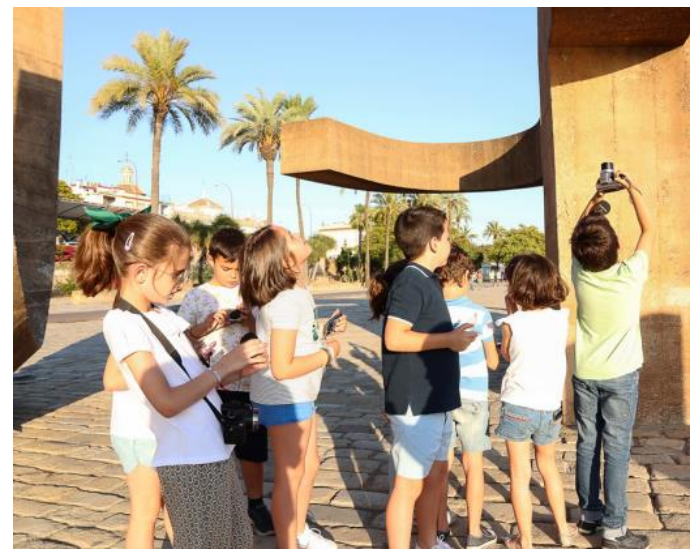

Figura 1: La construcción compartida del conocimiento artístico / Fotografía independiente / Autora (2019)

Son varios los autores (Bruner, 1997; Novak y Gowin, 1988) que subrayan la necesidad de atender a la totalidad de las dimensiones de la experiencia humana; pensamiento, sentimiento y acción. Teniendo en consideración la experiencia afectiva y social del aprendiz (Fig. 1) como una parte esencial en el proceso de enseñanzaaprendizaje y la construcción de significados dejando de ser considerados estos como una cuestión meramente cognitiva. Según exponen Novak y Gowin (1988), la predisposición para aprender destacada por Ausubel se relaciona íntimamente con la experiencia afectiva que el aprendiz percibe en el evento educativo. Es por ello por lo que, en su teoría de la educación ratifica que: "el aprendizaje significativo subyace a la integración constructiva del pensamiento, el sentimiento y la acción que tienen lugar en el aprendizaje humano y en la construcción de nuevos conocimientos" (p.109). Como fuente primera de los autores que comparten este modo de concebir la adquisición de conocimientos es posible citar a Bruner (1997) el cual asevera que: "No cabe ninguna duda que las emociones y los sentimientos están representados en los procesos de creación de significado y en nuestras construcciones de la realidad" (p.31).

En la vivencia que se facilita en este estudio y que cohesiona a los intervinientes: educadora y participantes, en una experiencia estética, artística y emocional se significa la idea del aprendizaje del arte como un hecho que no tiene por qué ser relegado en 
exclusividad al espacio y tiempo del salón de clase, sino que puede tener lugar en diversidad de contextos espaciales, temporales, culturales, sociales, etc., en los cuales se desarrolla el niño.

\section{Metodología}

Se explora el valor de la Investigación Basada en las Artes (IBA) fruto de las aportaciones de Elliot Eisner en 1993 entre otros autores (Barone y Eisner, 2012; Harper, 1994; Juanola y Masgrau, 2014; Marín Viadel, 2005, 2011) en contextos de descubrimiento y desarrollo compartido de conocimiento para desvelar los acontecimientos generadores del conocimiento artístico que tienen lugar en el proceso de enseñanza-aprendizaje intervenido por la obra escultórica de Eduardo Chillida ubicada en un espacio no museístico de la ciudad de Sevilla. Barone y Eisner (2012) afirman a este respecto "la investigación basada en artes era -y es- un intento de utilizar las formas de pensamiento y las formas de representación que proporcionan las artes como medio a través de las cuales el mundo puede ser comprendido mejor" (p.11). Junto con el IBA, el enfoque metodológico artográfico nacido de la mano de Rita Irwin y Alex de Cosson (2004; Marín Viadel, 2017), se establecen como un marco metodológico idóneo para acometer este tipo de experiencias artísticas educativas.

\section{Participantes}

Para alcanzar los objetivos investigadores planteados en el proyecto, el estudio se concreta "en el mundo empírico" (Blumer, 1982, p.16) con una experiencia práctica llevada a cabo con la colaboración de un grupo de 10 menores de edades comprendidas entre los 7 y 8 años, que cursan sus estudios de educación primaria en el mismo centro escolar y que habitualmente se relacionan dentro de este contexto formativo. Así mismo, la autora de este trabajo participa de la experiencia educativa como artistainvestigadora-educadora. Se determina necesario contar con la participación de un observador no interviniente en el acto educativo, para poder así documentar visualmente la experiencia desde una perspectiva ajena a los actores comprometidos en el proceso. 


\section{Propuesta educativa}

El proceso de trabajo seguido se asemeja al de la fotógrafa norteamericana Wendy Ewald, son menores los que intervienen en el proyecto como fotógrafos a la vez que espectadores, sujetos del acto educativo y creadores al tiempo que receptores (Ewald, 2007, 2015; Ewald y Ollman, 1993). Durante la realización del taller, los participantes e investigadora realizan fotografías para evidenciar lo vivenciado durante la apreciación y exploración de la escultura de gran formato situada en un espacio público, la obra Homenaje a la tolerancia de Eduardo Chillida (1992).

Se transmite a los participantes la idea de que la experiencia es una oportunidad para mostrar a los demás a través del empleo de las imágenes captadas, su particular manera de entender y experienciar el mundo y arte que les rodea (Bruner, 1997, 2001; Cassirer, 2004; Dewey, 2008; Goodman, 2005). Así pues, como resultado de estas indicaciones, los voluntarios desinhibidos muestran en las fotografías su personal perspectiva al respecto de la experiencia y su percepción de la obra contemporánea.

En consonancia con el proceso de trabajo descrito por la fotógrafa educadora que referencia este proyecto, no se instruye al alumnado acerca de cómo usar la cámara, así como tampoco se da ninguna pauta relativa a principios básicos de composición y elaboración de fotografías que pudiese condicionar el modo del espectador de representar la práctica.

Acerca del significado de la obra escultórica contemplada, en el imaginario colectivo de esta comunidad en interacción surge como no podría ser de otra manera, condicionado por el contexto sociocultural en el que habitan (Baeza, 2000; Castoriadis, 1995; Geertz, 2006; Pintos, 2005), la figura de una gran cabeza de toro. Para explicar la intención del artista en esta obra y un concepto abstracto como lo es el de la Tolerancia, tema recogido por la obra, la educadora-investigadora recurre al lenguaje gestual y al movimiento. Uno de estos gestos realizados germina y se convierte en una sucesión de manifestaciones afectivas entre los participantes que culmina en un abrazo grupal espontáneo donde es incluida la propia educadora como un miembro más perteneciente a esta comunidad social surgida en la actividad. De la misma manera, un hecho que enfatiza este gesto de aceptación e inclusión del adulto dentro de la subcomunidad creada es el constante acercamiento de los voluntarios que enseñan en 
todo momento lo que están viendo; sus percepciones y sus hallazgos, mientras la investigadora sujeta una cámara para documentar el proceso creativo de estos.

En este acto colectivo de apropiación del espacio urbano, los participantes hacen del vacío que subsiste entre los volúmenes un espacio social, y del tiempo compartido por el grupo en interacción y producción un tiempo también social (Heidegger, 2009). La actividad realizada que se concreta dota a la obra contemporánea de ciertas funciones que quizás pasaron por alto al creador de esta. El lugar habitado por los escolares genera una serie de sentimientos de identificación y apropiación, mientras la obra es fabulada y se carga de fantasías dejando de ser vista por los espectadores como un mero objeto escultórico. Mientras, la curiosidad de un compañero les hace a todos tomar conciencia de que existen aún mayores posibilidades de exploración; una forma que recoge y envuelve el espacio que en ese momento ya reconocen como suyo. Los participantes exploran el hormigón (Fig. 2) y su gran belleza estética, un material desconocido para estos al aparecer descontextualizado de su entorno constructivo y que no están habituados a ver en otras obras de arte.

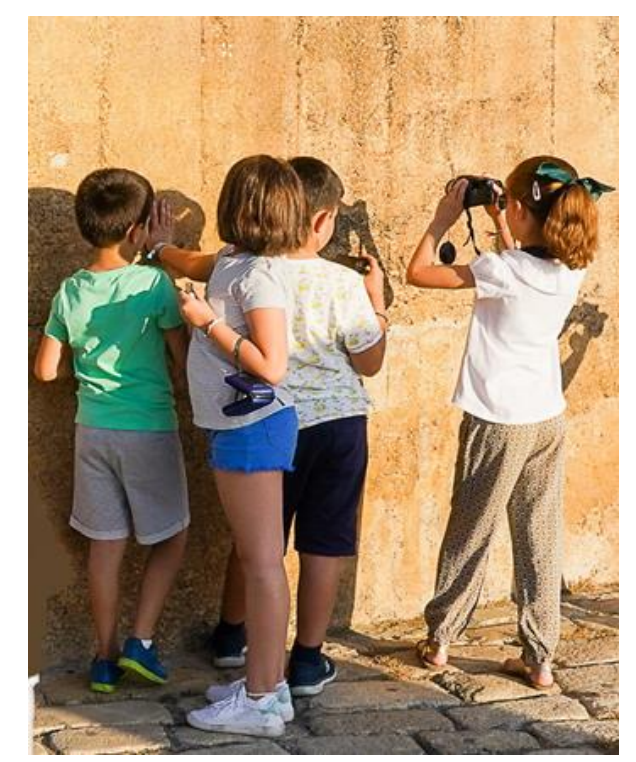

Figura 2: Explorando la materia que configura los límites del espacio y tiempo habitados / Fragmento de fotografía independiente / Autora (2019) 
Se considera pertinente mostrar los resultados finales a los voluntarios tras haber llevado a cabo el estudio. Al ver el producto resultante de la experiencia donde las fotografías de los participantes se entremezclan y fusionan con las de la artistainvestigadora-educadora estos lo perciben como un acto gratificante, además de reconocerse como productores de imágenes y no solo como consumidores de estas.

\section{Conclusiones}

En relación con la acción educativa que posibilita ilustrar las ventajas metodológicas del empleo del arte ubicado en el entorno urbano como recurso pedagógico, cabe significar que la interacción no solo con el arte sino al mismo tiempo con el otro, nos permiten generar una práctica interactiva para acercar a los intervinientes en la actividad a la obra observada. Con el empleo de estrategias tales como el trabajo en colaboración, el movimiento o la expresión gestual, etc., la escultura de Eduardo Chillida seleccionada es descubierta de una manera distinta, mediante una experiencia estética y educativa esencialmente intuitiva y sensorial. Mientras, la experiencia vivenciada permite recopilar diferentes perspectivas individuales de aquellos espectadores-creadores que experimentan el arte. Estas evidencias representan el importante papel que juegan la interación, la participación, la afectividad y las emociones en la construcción del conocimiento (artístico).

Con respecto a la Investigación Basada en las Artes se considera como una metodología eficaz para desvelar cuestiones educativas surgidas en contextos en contextos de descubrimiento y desarrollo compartido de conocimiento y que suelen quedar opacadas por otras metodologías no visuales. De la misma manera, en la investigación realizada con alumnado de la etapa de primaria, la a/r/tografía se identifica como una metodología poderosa frente a otras estrategias o instrumentos de cuestionamiento de la realidad que puedan ser empleados a estas edades y que darán lugar a respuestas de menor riqueza y complejidad. Por otro lado, los resultados obtenidos de la investigación $\mathrm{a} / \mathrm{r} /$ tográfica evidencian la equiparación entre el lenguaje visual y el lenguaje escrito, donde las imágenes fotográficas organizadas como unidad estética, a modo de fotoensayo, se constituyen en sistema de representación válido para la indagación en el contexto académico. 
En definitiva, el empleo de la fotografía en la práctica docente implementada nos sirve como herramienta pedagógica y medio de expresión visual, al tiempo que nos pertime el registro y evidencia de los procesos surgidos en el acto educativo. Tomando en consideración, la inclusión dentro de una misma narrativa de las distintas voces de los actores implicados en la experiencia, el resultado obtenido permite a la investigadora establecer un diálogo visual personal con otros en torno a las situaciones presentadas, la obra de arte contemplada y los significados atribuidos al espacio involucrado. 


\section{Referencias}

Ausubel, David P., Novak, Joseph D. y Hanesian, Helen (1987). Psicología educativa: un punto de vista cognoscitivo. México, México: Trillas.

Baeza, Manuel A. (2000). Los caminos invisibles de la realidad social: ensayo de sociología profunda sobre los imaginarios sociales. Providencia, Chile: Ril editores.

Barone, Tom, y Eisner, Elliot (2012). Arts based research. Thousand Oaks, Estados Unidos: Sage.

Benjamin, Walter, y Muñoz Milanés, José (2007). Sobre la fotografía. Valencia, España: Pre-Textos.

Blumer, Herbert (1982). El interaccionismo simbólico: perspectiva y método. Barcelona, España: Hora.

Bruner, Jerome. S. (1997). La educación, puerta de la cultura. Madrid, España: Visor.

Bruner, Jerome. S. (2001). Realidad mental y mundos posibles: los actos de la imaginación que dan sentido a la experiencia. Barcelona, España: Gedisa.

Cassirer, Ernest (2004). Antropología filosófica: introducción a una filosofía de la cultura. Colección Popular (41). México, México: Fondo de Cultura Económica.

Castoriadis, Cornelius (1995). Los dominios del hombre: las encrucijadas del laberinto. Barcelona, España: Gedisa.

Castro-León, Elke (2017). El mundo conceptual del alumnado de educación artística. Tesis doctoral inédita. Universidad de Sevilla, España. http://hdl.handle.net/11441/54384

Coll, César (1991). Aprendizaje escolar y construcción del conocimiento. Barcelona, España: Paidós.

Colomina, Rosa y Onrubia, Javier (2001). Interacción educativa y aprendizaje escolar: la interacción entre alumnos. En Desarrollo psicológico y educación (pp. 415-436). Madrid, España: Alianza.

Dewey, John (2002). Democracia y educación: una introducción a la filosofía de la educación. Madrid, España: Morata.

Dewey, John (2004). Experiencia y educación. Madrid, España: Biblioteca Nueva.

Dewey, John (2008). El arte como experiencia. Barcelona, España: Paidós. 
Ewald, Wendy (2007). Thirty Years of Collaborating with Children. Visual Arts Research, 33(2), 21-23. Recuperado de http://www.jstor.org/stable/20715445

Ewald, Wendy (2015). This is where I live. Londres, Inglaterra: MACK.

Ewald, Wendy, y Ollman, Arthur (1993). Wendy Ewald: Portraits and Dreams. Photographs by Mexican Children. Nueva York, Estados Unidos: George Eastman House.

Geertz, Clifford (2006). La interpretación de las culturas. Barcelona, España: Gedisa.

Goodman, Nelson (2005). Maneras de hacer mundos. Madrid, España: Visor.

Harper, Douglas (1994). On the authority of the image: Visual methods at the crossroads. En Norman. K. Denzin y Yvonna S. Lincoln (Eds.) Handbook of qualitative research (pp. 403-412). Thousand Oaks, Estados Unidos: Sage.

Heidegger, Martín (2009). El arte y el espacio. Barcelona, España: Herder.

Irwin, Rita L., y De Cosson, Alex (Eds.) (2004). A/r/tography: Rendering Self Through ArtsBased Living Inquiry. Vancouver, British Columbia: Pacific Educational Press.

Juanola, Roser, y Masgrau, Mariona (2014). Las aportaciones de E. W. Eisner a la educación: un profesor paradigmático como docente, investigador y generador de políticas culturales. En Revista Española de Pedagogía, 72 (259), 493-508.

Marín Viadel, Ricardo (2005). La «investigación educativa basada en las artes visuales» o "arteinvestigación educativa». En Ricardo Marín Viadel (Ed.) Investigación en educación artística: temas, métodos y técnicas de indagación sobre el aprendizaje y la enseñanza de las artes y culturas visuales, (pp. 223-274). Granada, España: Universidad de Granada y Universidad de Sevilla.

Marín Viadel, Ricardo. (2011). Las investigaciones en educación artística y las metodologías artísticas de investigación en educación: temas, tendencias y miradas. Educação, 34 (3), 271-285. Brasil: Pontifícia Universidade Católica do Rio Grande do Sul Porto Alegre. http://www.redalyc.org/articulo.oa?id=84820027003

Marín Viadel, Ricardo (2017). A/r/tografía Social: un enfoque metodológico en el contexto de las investigaciones sobre Artes Visuales y Educación. En Ricardo Marín Viadel y Joaquín Roldán (Eds.), Ideas visuales: Investigación basada en artes $e$ investigación artística (pp. 30-45). Granada, España: Universidad de Granada. 
Moreira, Marco A. (2000). Aprendizaje significativo: teoría y práctica. Madrid, España: Visor.

Orden ECD/65/2015, de 21 de enero, por la que se describen las relaciones entre las competencias, los contenidos y los criterios de evaluación de la educación primaria, la educación secundaria obligatoria y el bachillerato. Boletín Oficial del Estado, 25, de 29 de enero de 2015, 6986 a 7003. Recuperado de https://www.boe.es/boe/dias/2015/01/29/pdfs/BOE-A-2015-738.pdf

Piaget, Jean (2012). La equilibración de las estructuras cognitivas: problema central del desarrollo. Madrid, España: Siglo XXI de España.

Pintos, Juan L. (2005). Comunicación, construcción de la realidad e imaginarios sociales. Utopía y Praxis Latinoamericana, 10 (29), 37-65.

Vygotski, Lev (1984). Aprendizaje y desarrollo intelectual en la edad escolar. Infancia y Aprendizaje: Journal for the Study of Education and Development, 27-28, 105-116. https://doi.org/10.1080/02103702.1984.10822045

Vygotski, Lev (1995). El desarrollo de los procesos psicológicos superiores. Barcelona, España: Crítica. 